\title{
Ideias, instituições e coalizões: as razões do fracasso da política industrial lulista
}

\author{
Ideas, institutions and coalitions: the reasons \\ for the failure of Lulista industrial policy
}
MICHELLI GONÇALVES STUMM**** WELLINGTON NUNES,+++ RENATO PERISSINOTTO ${ }^{\times}, \times \times$

\begin{abstract}
RESUMO: Este artigo trata da política industrializante dos governos Lula, com o objetivo de explicar por que ela fracassou. Isso é feito em três momentos distintos. Primeiramente, tratamos das ideias que orientaram as políticas industriais do período. Em segundo lugar, mostramos, com base em conjunto sintético de informações, que os objetivo pretendidos, em sua maioria, não foram alcançados. Finalmente, analisamos o insucesso dessas políticas como base na ausência de viabilidades (intelectual, administrativa e política) do conjunto de ideias que norteou o empreendimento.
\end{abstract}

PALAVRAS-CHAVE: Política industrial; governos Lula; abordagem ideacional.

ABSTRACT: This article deals with the industrializing politics of the Lula governments, in order to explain why it failed. This is done at three different times. First, we deal with the ideas that guided the industrial policies of the period. Secondly, we show, based on a synthetic set of information, that the intended objectives, for the most part, were not achieved. Finally, we analyze the failure of these policies as a basis in the absence of viability (intellectual, administrative and political) of the set of ideas that guided the enterprise.

KEYWORDS: Industrial policy; Lula governments; ideational approach.

JEL Classification: O25.

\footnotetext{
* Programa de Pós-Graduação em Ciência Política (PPGCP) da Universidade Federal do Paraná (UFPR), Curitiba/PR, Brasil. E-mail: michellistumm@gmail.com. Orcid: 0000-0001-8042-3721.

* Mestra em Sociologia pela Universidade Federal do Paraná e Doutoranda em Ciência Política pela mesma universidade.

+ Programa de Pós-Graduação em Ciência Política (PPGCP) da Universidade Federal do Paraná (UFPR), Curitiba/PR, Brasil. E-mail: 4gton_nunes@yahoo.com.br. Orcid: 0000-0002-9344-7324.

++ Doutor em Sociologia pela Universidade Federal do Paraná e atualmente participa de um programa de pós-doutoramento em ciência política pela mesma instituição.

× Professor do Programa de Pós-Graduação em Ciência Política (PPGCP) da Universidade Federal do Paraná (UFPR), Curitiba/PR, Brasil. E-mail: monseff@gmail.com. Orcid: 0000-0001-8747-7976.

${ }^{x \times}$ Doutor em Ciências Sociais pela Universidade Estadual de Campinas - Unicamp, e professor do Departamento de Ciência Política da Universidade Federal do Paraná - UFPR. É pesquisador do CNP2, nível 2. Submetido: 20/ Agosto/2018.; Aprovado: 12/Fevereiro/2019.
} 


\section{INTRODUÇÃO ${ }^{1}$}

Uma ampla literatura no campo do neoinstitucionalismo histórico tem mostrado a importância de se levar em consideração as ideias dos atores políticos para entender as suas decisões (Hay 2011; Goldstein \& Keohane 1993; Berman 1998; Blyth 2003; Blyth 2001; Schmidt 2010; Schmidt 2011)². Para essa literatura, filiada ao neoinstitucionalismo discursivo, a inclusão das ideias nas explicações dos fenômenos políticos teria, ao menos, uma dupla vantagem.

Primeiramente, permitiria fugir à recorrente antinomia encontrada nas ciências sociais entre "interesses objetivos" e "ideias". Segundo essa antinomia, os interesses existiram por si sós como a expressão de posições objetivas na estrutura social. As ideias, por sua vez, seriam apenas disfarces ideacionais para interesses que operam por detrás delas. Recusar essa antinomia significa dizer que nenhum interesse existe separadamente da representação que os atores sociais e políticos têm deles, o que, por sua vez, equivale a dizer que as ideias são uma variável explicativa de direito próprio, sendo possível, portanto, formular uma teoria ideacional dos fatos políticos.

Em segundo lugar, a afirmação de que "as ideias contam" permitiria explicar processos de mudança social e política que ocorressem de maneira incremental, uma dificuldade, segundo essa literatura, que os textos paradigmáticos do neoinstitucionalismo histórico enfrentam com frequência. Os autores filiados ao neoinstitucionalismo discursivo afirmam que a identificação de grandes parâmetros institucionais não é suficiente para entender por que os atores políticos fazem o que fazem. Não há dúvida, dizem, que as instituições são constrangimentos importantes e, pela via da path dependence, aumentam a possibilidade de determinados resultados em detrimento de outros. No entanto, mesmo quando determinados parâmetros permanecem, mudanças internas e opções diferentes surgem na medida em que novos atores e novas ideias aparecem, instaurando um debate discursivo que pode reorientar o sentido das políticas públicas.

No entanto, a defesa dessas proposições não se traduz numa perspectiva radicalmente idealista. Ao contrário, junto com a proposição de que levar as ideias a sério significa defender que elas operam como variáveis explicativas de direito próprio, afirma-se também que determinadas ideias, por mais que se apropriem dos corações e mentes de atores sociais estratégicos, precisam encontrar-se com certas condições que viabilizem a sua vitória política definitiva. Muitos autores discutiram as condições políticos institucionais, de incerteza e de path dependence que favorecem ou dificultam as chances de vitória de um conjunto de ideias (Kingdon 2014; Campbell 1998; Beland 2005; Gourevitch 1989; Hogan \& O’Rourke 2014; Goldstein \& Keohane 1993; Cox \& Béland 2013; Goldstein 1993; Heclo 1974). No entanto, foi Peter Hall $(1986,1989)$ que ofereceu, a nosso ver, o mais sistematizado e paradigmático modelo analítico para pensar a viabilidade das ideias.

\footnotetext{
${ }^{1}$ Os autores agradecem o suporte do CNPq e da Capes, respectivamente.

2 Para um recenseamento exaustivo dessa literatura, ver Perissinotto e Stumm, 2017.
} 
Segundo esse autor, três são as condições que viabilizam ideias. Primeiramente, a viabilidade intelectual, isto é, quando determinadas ideias (sobretudo, no caso dele e do nosso, ideias econômicas) dependem do reconhecimento das teorias existentes, isto é, de uma comunidade epistêmica vinculada à área decisória em questão que avalie a robustez teórica de tais ideias; em segundo lugar, as ideias devem adquirir viabilidade administrativa, isto é, serem recebidas por agências estatais com poder de agenda e de decisão; e, por fim, viabilidade política, quando conseguem ser sustentadas por uma coalizão que se reconhece, por razões de interesse ou por razões puramente ideacionais, naquelas ideias.

Este artigo se orienta por esse espírito teórico e pretende responder à seguinte questão: que ideias orientaram a formulação da política industrial dos governos Lula e por que ela fracassou? Para tanto, o texto divide-se em três partes: na primeira delas, mostramos, por meio de uma análise dos documentos governamentais, as ideias que orientaram a formulação da política industrial daquele período; em seguida, revelamos, por meio da análise de alguns indicadores, que as intenções ali presentes não se traduziram em resultados condizentes; e, na terceira parte, procuramos encontrar as razões do fracasso seguindo as sugestões de Peter Hall, isto é, analisando a qualidade do desenho das políticas, a qualidade do processo decisório (isto é, da institucionalidade criada para implementá-la) e a natureza da coalizão formulada para lhe dar sustentação. Por fim, na conclusão, sintetizamos os achados do artigo. Desse modo, acreditamos que o presente texto contribui para a discussão sobre a importância de fatores não econômicos para o pleno entendimento da política industrial no país. Em alguma medida, a literatura especializada já se refere a eles (Suzigan \& Furtado 2006; De Toni 2013, 2015). Nosso artigo, porém, pretende colocá-los no centro da discussão, conferindo-lhes um tratamento mais sistemático.

\section{POLÍTICA INDUSTRIAL NO PLANO TEÓRICO: AS IDEIAS}

Política industrial é, provavelmente, um dos temas mais controversos na literatura sobre economia política. Uma das razões para isso, conforme observado por Mansueto Almeida, é que a ideia de política industrial em si mesma contraria um conceito clássico da teoria econômica, o das vantagens comparativas, elaborado pelo economista britânico David Ricardo. Segundo esse conceito, os países ao redor do mundo deveriam se concentrar na produção daqueles produtos para os quais fossem detentores de vantagens comparativas. Isso feito, o consumo e o bem-estar da população mundial poderiam ser maximizados através da expansão do comércio internacional (Almeida 2009, pp. 8-9).

A principal crítica que se faz a essa teoria diz respeito ao seu caráter estático. Isto porque os custos de oportunidade, utilizados para definir em quais produtos determinado país possui vantagens comparativas, são atribuídos de forma fixa isto é, sem levar em conta suas eventuais transformações ao longo do tempo. Nesse sentido, como demonstram eloquentemente os cases desenvolvimentistas - sejam 
eles latino-americanos ${ }^{3}$ ou asiáticos ${ }^{4}$ - vantagens comparativas são dinâmicas, ou seja, podem ser criadas e/ou transformadas. Portanto, a questão que tem informado o debate atual em torno da política industrial não tem a ver com fazer ou não uso desse tipo de expediente, mas sim com a forma de utilizá-lo (Rodrik 2007). O referido debate, naturalmente, tem sido informado pelas duas perspectivas teóricas mencionadas acima - conforme observado em diversos trabalhos (ver, por exemplo, Almeida 2009; Coutinho et al. 2012; Peres \& Primi 2009; Schapiro 2013) ${ }^{5}$.

Assim, à perspectiva que enxerga o processo concorrencial de maneira estática, no qual as vantagens comparativas estão dadas, corresponde uma abordagem de política industrial centrada na correção das falhas de mercado - segundo a qual os governos devem fazer uso de políticas (predominantemente) horizontais (i.e., sem distinção entre os setores econômicos) para permitir que os agentes econômicos possam maximizar seus interesses, tendo em vista suas respectivas vantagens comparativas. Por sua vez, as medidas práticas, nesse tipo de abordagem, devem ter como objetivo a padronização das regras do jogo, a desobstrução de gargalos infraestruturais, a correção de eventuais distorções mercadológicas, etc.

Por outro lado, à perspectiva que enxerga o processo concorrencial de forma mais dinâmica, no qual as vantagens comparativas podem ser criadas e/ou modificadas, corresponde uma abordagem de política industrial de viés transformador, baseada em políticas (predominantemente) verticais (i.e., com distinção entre os setores econômicos), destinadas a criar vantagens comparativas, via inovação constante em processos e produtos. Entre os exemplos de medidas geralmente utilizadas nesse tipo de abordagem estão a formação de grandes grupos nacionais em setores estrategicamente selecionados, a promoção de setores portadores de futuro, massificação da educação, investimentos progressivos em inovação e na produção de novas tecnologias, entre outras. O objetivo desta seção é justamente mostrar que tipo de abordagem teórica orientou a política industrial dos governos Lula.

\section{As ideias da política industrial lulista}

Utilizamos como indicadores o conteúdo de três documentos produzidos no período Lula: o Programa de Governo utilizado para disputar as eleições de 2002 e os dois Planos Plurianuais (PPA 2004-2007 e PPA 2008-2011). O primeiro desses documentos foi utilizado como uma espécie de "carta de intenções”, com vistas a

\footnotetext{
${ }^{3}$ Ver, entre tantos outros, Bielschowsky (1988); Bresser-Pereira (2011, 2006); Fonseca (2014, 1998); Schneider (1999).

${ }^{4}$ Entre muitos outros, ver Amsden (2001, 1989); Evans (1992); Johnson (1982); Wade (1990); Woo-Cumings (1999).

${ }^{5}$ Além do debate acima mencionado, a literatura apresenta quatro eixos de defesa para justificar a implementação de políticas industriais: (i) proteção da indústria nascente; (ii) correção de falhas de mercado; (iii) geração de externalidades positivas sobre a economia; (iv) produção de economias de aglomeração. Entre os argumentos contrários à implementação de políticas industriais estão: (i) possibilidade de corrupção e rent-seeking; (ii) falta de capacidade estatal (Naude, 2010; Pack \& Saggi 2006).
} 
identificar o rumo que seus formuladores pretendiam seguir. Já os planos plurianuais, como se sabe, constituem o principal instrumento de planejamento de médio prazo à disposição dos ocupantes do governo.

O objetivo geral dos formuladores da estratégia de desenvolvimento inaugurada em 2003 era gerar um "círculo virtuoso" entre investimento e consumo, a partir da incorporação progressiva de famílias ao mercado consumidor - via utilização de políticas sociais focalizadas, expansão da massa salarial, pulverização de serviços bancários, etc. Para que isso fosse possível, além dessa "dimensão social", a estratégia em questão também contava com uma "dimensão nacional”, cujo objetivo principal era recuperar o setor produtivo nacional - algo imprescindível tanto para a sustentação da estratégia proposta quanto para que se pudesse expandir a produtividade e o progresso técnico da economia nacional (Nunes 2018).

Essa recuperação do setor produtivo, por sua vez, demandaria, conforme previsto já no programa de governo, "políticas ativas" em três frentes: i) capacitação tecnológica das empresas nacionais (tanto privadas quanto públicas); ii) reconstrução da infraestrutura econômica; iii) ampliação das fontes internas de financiamento, com vistas a superar a recorrente dependência de recursos externos (Programa de Governo 2002, pp. 32-33).

Essas três frentes de atuação, ainda de acordo com o documento, demandariam políticas em dois níveis distintos. No primeiro deles, as medidas deveriam ser "horizontais”, por não requererem “a identificação de setores líderes”, uma vez que se tratava basicamente de ampliar a estrutura produtiva existente e de configurar "um ambiente econômico" que conduzisse "ao aumento constante da competitividade do País”. Nesse nível horizontal, portanto, as medidas deveriam ir ao encontro de objetivos como manter a estabilidade de preços, tornar o sistema tributário mais eficiente, melhorar o nível da educação e da qualificação da mão de obra e expandir os investimentos em infraestrutura (Idem, pp. 34-35).

No segundo nível, por sua vez, as medidas deveriam ser de outra natureza. Isto porque o objetivo não seria mais ampliar a estrutura produtiva existente, mas transformá-la. Nos termos do documento, o governo deveria "incentivar uma profunda mudança estrutural nos sistemas produtivos, especialmente aqueles intensivos em alta tecnologia". Para tanto, as políticas deveriam ser predominantemente verticais - isto é, capazes de priorizar alguns setores econômicos em detrimento de outros - com vistas a promover tanto o desenvolvimento de setores específicos (como aqueles com maior potencial de difusão tecnológica e os portadores de futuro) quanto a expansão da inovação. Assim, de acordo com o documento, a "nova política industrial" deveria ser:

(a) planejada nacionalmente a partir das potencialidades regionais; (b) seletiva e vertical; (c) formada a partir da explicitação de metas a serem atingidas pelas empresas como contrapartida do apoio público; (d) baseada na transparência dos custos envolvidos e do retorno que a economia do País poderá receber; (e) orientada pela cobrança de desempenho e metas publicamente fixadas; (f) definida no tempo; (g) transparente à opinião pública (Idem, pp. 35-36). 
É possível dizer, portanto, que dois tipos de medidas estavam previstas na estratégia inaugurada em 2003, no que se refere ao setor produtivo nacional. De um lado, pretendia-se utilizar um conjunto de medidas horizontais com vistas a melhorar o ambiente econômico e ampliar a estrutura produtiva existente. De outro, a intenção era fazer uso de medidas verticais capazes de priorizar setores considerados estratégicos para a difusão do progresso técnico e da inovação. Conforme sintetizado no próprio documento, seria preciso "combinar as políticas horizontais voltadas para o mercado interno com as verticais e setoriais, voltadas para a capacitação tecnológica e às exportações” (Idem, p. 36).

Essa intenção de articular esses dois tipos de políticas também esteve presente no planejamento de médio prazo do governo - isto é, no PPA (2004-2007), que se baseou amplamente no programa de governo de 2002 (Brasil 2003), e no PPA (2008-2011), que reafirmou o compromisso com a estratégia inaugurada em 2003 (Brasil 2007).

As políticas industrial, tecnológica e de comércio exterior previstas no PPA (2004-2007) tinham como principais objetivos "o aumento da eficiência econômica, a melhor inserção no comércio mundial e o desenvolvimento e a difusão de tecnologias com maior potencial de indução do nível de atividade e de competição no comércio mundial”. Para que isso fosse possível, previa-se atuação em duas frentes. Em primeiro lugar, seria preciso ter como alvo os chamados "determinantes da produtividade sistêmica”.

Como a infraestrutura física (transporte, logística, energia e telecomunicações); a infraestrutura de ciência e tecnologia (pesquisas básica e aplicada e engenharia, normatização e padrões técnicos para bens e serviços); a educação e qualificação da mão de obra; e marcos regulatórios adequados à realização de contratos financeiros para a prestação de serviços de utilidade pública (Brasil 2003, pp. 99 e 97)

Em segundo lugar, seria preciso mirar naqueles segmentos que fossem "transmissores e geradores de progresso técnico"; que envolvessem "elevada intensidade de conhecimento científico e tecnológico"; e que fossem "importantes para o futuro do País e nos quais o Brasil apresentasse potencial para o desenvolvimento de vantagens comparativas dinâmicas: nanotecnologia, software, biotecnologia, fármacos e medicamentos e bens de capital" (Idem, p. 99).

O PPA 2008-2011, por sua vez, ao reafirmar o compromisso do governo com a estratégia inaugurada em 2003, também insistia, em termos de política industrial e tecnológica, em objetivos semelhantes aos elencados anteriormente. De um lado reiterava a necessidade de se melhorar a eficiência do ambiente econômico do país - como, por exemplo, implantar "uma infraestrutura eficiente e integradora do Território Nacional". De outro, insistia que a sustentação de um modelo centrado na ampliação constante dos investimentos, da produtividade e da competitividade "exige forte promoção da inovação tecnológica na produção de bens e serviços, implementação de políticas de incentivo à pesquisa e ao desenvolvimento e a setores e atividades intensivos em tecnologia, geradores e difusores de inovação" (Brasil 2007, pp. 91 e 12). 
Adicionalmente, partia-se do princípio que o processo de acirramento da competição internacional, com ampliação progressiva da demanda por produtos e processos diferenciados, exigiria que o Brasil agregasse "cada vez mais valor à sua pauta de exportação, como forma de garantir inserção mais dinâmica no mercado mundial". Nesse tipo de cenário, por sua vez, "a rapidez de aprendizagem e a capacidade de inovação tecnológica e de aumento da produtividade" seriam "vantagens competitivas a serem perseguidas pelos setores produtivos do País”.

Como se percebe, tal qual ocorrido com as intenções iniciais declaradas no Programa de Governo de 2002, o planejamento de médio prazo dos dois governos Lula também apontava na direção da necessidade de dois conjuntos distintos de políticas. Um deles deveria reunir aquelas políticas destinadas a nivelar o campo de jogo - aumento da eficiência econômica, uniformização de regras e procedimentos, incremento progressivo das infraestruturas, etc. O outro precisaria conter aquelas políticas projetadas para promover deliberadamente tanto o desenvolvimento tecnológico das empresas quanto o investimento progressivo em inovação - construção de grandes grupos nacionais em setores estratégicos, ampliação progressiva dos investimentos em P\&D, desenvolvimento dos setores portadores de futuro, etc.

\section{A PRÁTICA DA POLÍTICA INDUSTRIAL LULISTA: CONSTATANDO O FRACASSO}

Permeado por intenso debate acerca dos rumos da política industrial brasileira, nos primeiros meses de mandato do governo Lula, foram lançados dois manifestos assinados por diversos órgãos federais: (i) Roteiro para Agenda de Desenvolvimento e (ii) Diretrizes de Política Industrial, Tecnológica e de Comércio Exterior. Tais documentos influenciaram a construção da política industrial lulista: a Política Industrial, Tecnológica e de Comércio Exterior (PITCE) de 2004 e a Política de Desenvolvimento Produtivo (PDP) de 2008, conforme sistematizado no Quadro 1.

Ainda que diversos autores apontem a superação do viés liberal como a principal faceta da política industrial desse período ${ }^{6}$, a grande maioria elege a inovação como mudança determinante, principalmente em função: (i) da "criação de setores intensivos em tecnologia" e do "fomento à inovação nos setores portadores de futuro (biomassa, nano e biotecnologia) e prioritários (semicondutores, software, bens de capital e fármacos), nos quais o Brasil ainda não é competitivo" (Almeida 2009 , p. 23); (ii) do incentivo à "mudança do patamar competitivo da indústria brasileira rumo à diferenciação e inovação de produtos, estratégia competitiva" (Salerno 2004, p. 14); (iii) da "sinergia da política industrial com a de comércio exterior e foco na inovação" (Coronel et al. 2014, p. 113) e (iv) do "deslocamento

\footnotetext{
${ }^{6}$ Ver, entre outros: Suzigan \& Furtado (2006); Almeida (2009, 2011); Ferraz (2009); Coronel et. al. (2014).
} 
Quadro 1: Características da Política Industrial Lulista

\begin{tabular}{l|l|l}
\hline Data & $\begin{array}{c}\text { Política Industrial, Tecnológica e } \\
\text { de Comércio Exterior (PITCE) }\end{array}$ & \multicolumn{1}{|c}{ Política de Desenvolvimento Produtivo (PDP) } \\
\hline Vigência & $2004-2007$ & $12 / 05 / 2008$ \\
\hline Mandato & Lula I (2003-2006) & $2008-2010$ \\
\hline Objetivo & $\begin{array}{l}\text { Fortalecer e expandir a base } \\
\text { industrial brasileira por meio da } \\
\text { melhoria da capacidade inovadora } \\
\text { das empresas. }\end{array}$ & $\begin{array}{l}\text { Fortalecer a economia do país, sustentar o } \\
\text { crescimento e incentivar a exportação. }\end{array}$ \\
\hline Setores & $\begin{array}{l}\text { Definiu dois grupos de setores: } \\
\text { (i) os estratégicos (software, } \\
\text { semicondutores, bens de capital } \\
\text { e fármacos \& medicamentos); } \\
\text { (ii) os portadores de futuro } \\
\text { (biotecnologia, nanotecnologia, } \\
\text { biomassa e energias renováveis). }\end{array}$ & $\begin{array}{l}\text { No plano, 24 segmentos industriais } \\
\text { foram divididos da seguinte forma: (i) } \\
\text { aqueles com efeito mobilizador em áreas } \\
\text { estratégicas; (ii) aqueles direcionados à } \\
\text { consolidação e expansão da liderança; } \\
\text { (iii) aqueles voltados ao fortalecimento } \\
\text { da competitividade. }\end{array}$ \\
\hline
\end{tabular}

Fontes: Brasil (2016b); Brasil (2016a); Salerno \& Daher (2006).

da ênfase da política industrial da substituição de importações para a constituição de capacidades e competências" (Suzigan \& Furtado 2006, p. 178).

De acordo com esses atores, parece inegável que os governos de Lula foram marcados por uma guinada em relação às políticas industriais, caracterizada por certo ativismo estatal. Assim, o grande mérito foi, sem dúvida, a reinserção do desenvolvimento industrial na agenda de políticas públicas e o reconhecimento da indústria como vetor de desenvolvimento econômico (Ferraz 2009; Suzigan \& Furtado 2006; Almeida 2011; Coronel et al. 2014; Almeida 2009).

No entanto, ainda que esses governos se mostrassem favoráveis à utilização de políticas industriais, as medidas propostas estiveram longe de atingir os resultados pretendidos, alcançando menos da metade das metas estabelecida. Os objetivos não concretizados diziam respeito a aspectos importantes como aumento das exportações, elevação dos investimentos, acréscimo de valor agregado e ampliação da escolaridade dos trabalhadores (Stumm 2016).

Além desse balanço negativo, as ações propostas não alteraram a estrutura industrial brasileira. Como pode ser observado no gráfico a seguir (Gráfico 1), a representatividade do setor industrial na produção, nos empregos e nas importações se manteve inalterada no momento de implementação da política e em períodos posteriores. A retração mais acentuada nas exportações, que teve diminuição de $20 \%$ no período, revela outro problema que as políticas industriais lulistas não conseguiram atacar: a desindustrialização ${ }^{7}$.

\footnotetext{
${ }^{7}$ Conceitualmente entendida como diminuição intensiva da indústria no montante de empregos, produção e exportações de determinada localidade geográfica ou setor industrial (Morceiro 2012).
} 
Iniciado nos anos 1980 e intensificado na década de 2000, o fenômeno da desindustrialização brasileira apresenta características da "doença holandesa", pois o encolhimento industrial se dá pelo aumento da participação dos setores agrícolas, minerais e agroindustriais, resultando em um processo de reprimarização da economia ou de especialização regressiva (Bresser-Pereira 2007; Oreiro \& Feijó 2010). De acordo com Bresser-Pereira \& Marconi (2009), em países como o Brasil, que ainda não atingiram um grau de industrialização satisfatório, a doença holandesa implica baixo crescimento e expansão progressiva da pobreza, anulando eventuais efeitos positivos das políticas industriais.

\section{Gráfico 1: Participação da Indústria nos Principais Indicadores de Desempenho Econômico (2002-2014) ${ }^{8}$}

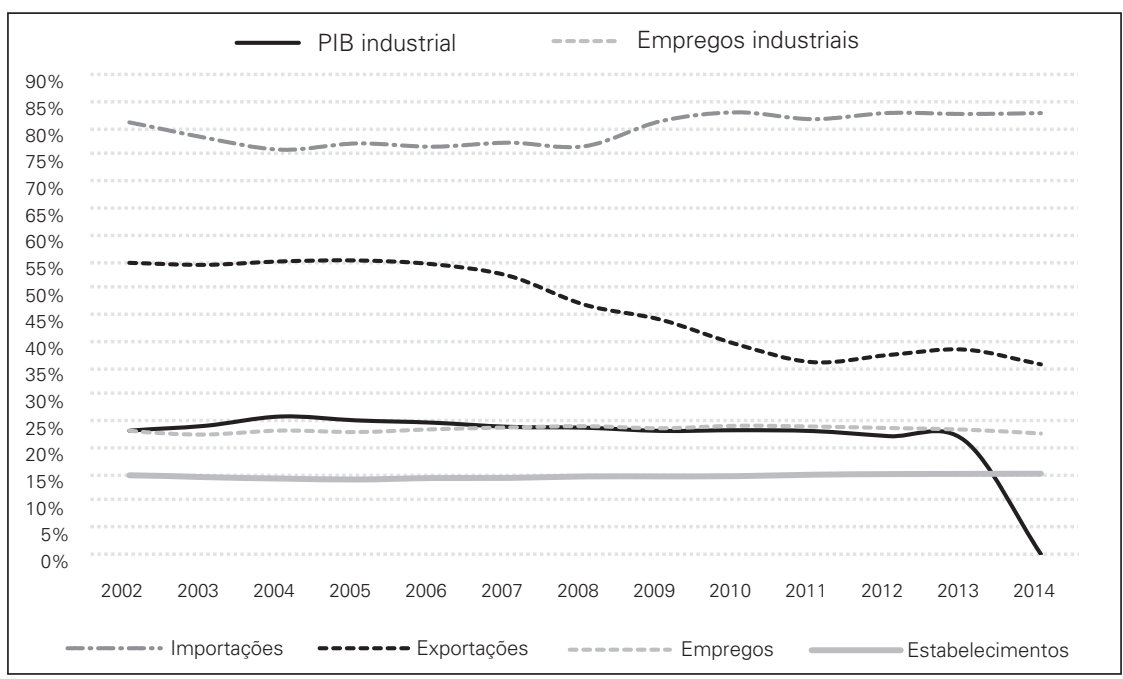

Fontes: Stumm (2016), a partir de IBGE (2013); BRASIL (2016a); BRASIL (2016b).

No contexto internacional, os objetivos da política industrial lulista de melhorar a capacidade inovadora das empresas, fortalecer a economia do país, incentivar as exportações e alavancar a competitividade nos mercados interno e externo também apresentaram baixa efetividade ${ }^{9}$, conforme demonstrado pelos dois gráficos a seguir.

\footnotetext{
${ }^{8}$ Levando-se em conta que os efeitos de determinada política industrial tendem a exceder o seu período de implementação, estendemos o recorte cronológico dos Gráficos 1, 2 e 3 até o ano de 2014, último ano do primeiro governo Dilma, embora nossa análise se restrinja aos governos Lula.

${ }^{9}$ Embora não seja o objetivo deste artigo, é importante lembrar que, além da inefetividade do ponto de vista dos resultados, a política industrial do governo Lula foi fortemente financiada por gastos tributários e renúncias fiscais, que, surpreendentemente, foram destinados em maior quantidade a setores tradicionais da indústria nacional (como a Zona Franca de Manaus, no caso dos gastos tributários, e a indústria automobilística, no caso das renúncias fiscais) e não para atividades de inovação. Essa estratégia, avalia-se hoje, é um importante componente da nossa crise fiscal. Sobre esse ponto, ver (Curado \& Curado 2016).
} 
Gráfico 2: Posicionamento do Brasil nos Principais Indicadores de Desempenho Industrial Externo

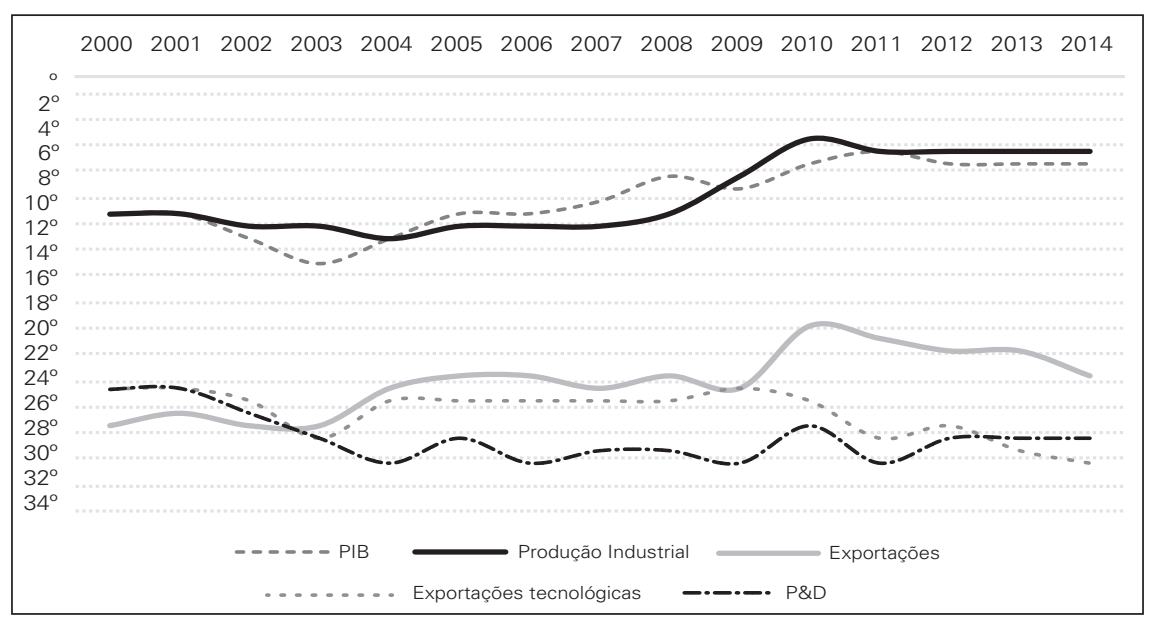

Fontes: (Stumm 2016), a partir de FMI (2016); OCDE (2016); UNIDO (2016).

No ranking mundial dos principais indicadores de desempenho industrial, apesar de ter ganhado posições em variáveis de volume, como PIB e produção industrial, o Brasil perdeu espaço em quesitos mais qualitativos como exportações tecnológicas, pesquisa e desenvolvimento (ver Gráfico 2).

No que diz respeito à competitividade, inovação e complexidade econômica, o desempenho brasileiro no ranqueamento mundial também não apresentou melhoras significativas nos últimos anos (ver Gráfico 3).

Gráfico 3: Posicionamento do Brasil nos Principais Índices de Competitividade, Inovação e Complexidade Econômica

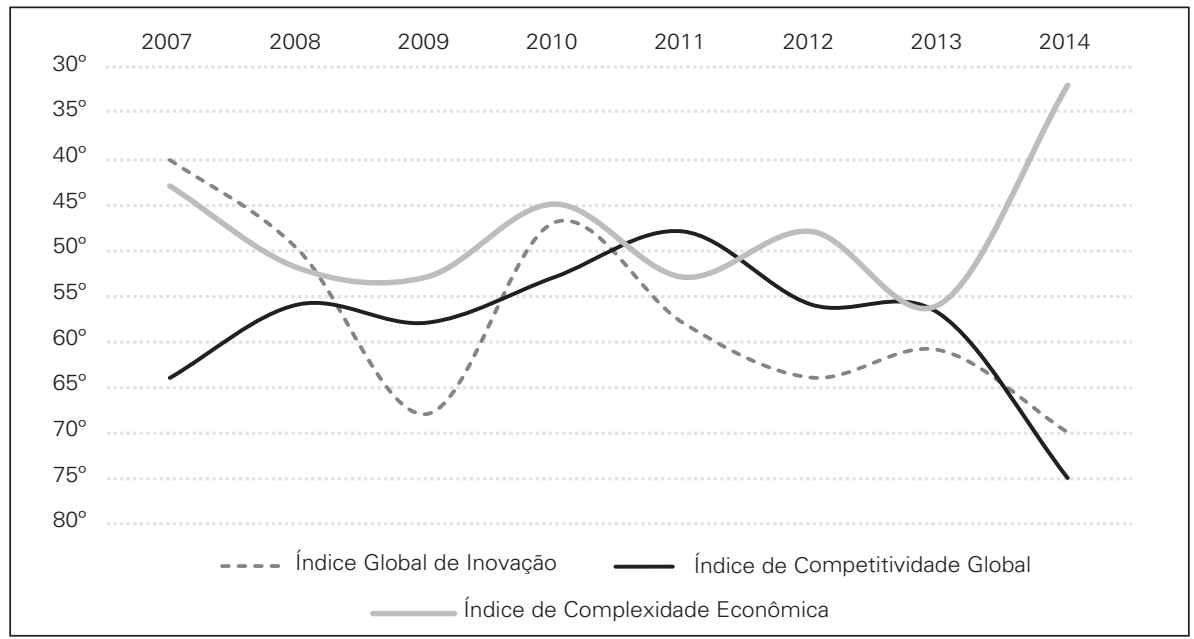

Fontes: Stumm (2016), a partir de WORLD ECONOMIC FORUM (2016a); WORLD ECONOMIC FORUM (2016b); CORNELL UNIVERSITY et al. (2016). 
No que diz respeito aos meios utilizados para implementação, é preciso registrar que a política industrial do período em análise foi acompanhada por uma complexa rede de instrumentos. A partir de 2004, importantes pessoas jurídicas ${ }^{10}$ foram criadas, marcos legais ${ }^{11}$ estabelecidos, instrumentos de desoneração ${ }^{12}$ e financiamento ${ }^{13}$ implementados e consideráveis investimentos governamentais ${ }^{14}$ foram realizados (Stumm 2016). Além dessa estrutura, foi construída uma arena tripartite, o Conselho Nacional de Desenvolvimento Industrial (CNDI) $)^{15}$, e a Agência Brasileira de Desenvolvimento Industrial (ABDI) - concebendo a política industrial de forma bottom-up e sua implementação de maneira top down.

Esses instrumentos de implementação e tomada de decisão mostram que o Estado buscou certa inserção com setores importantes da sociedade - notadamente com setores empresariais - procurando fornecer canais institucionalizados de (re)negociação de políticas industriais. No entanto, quando se considera, simultaneamente, meios de implementação e resultados alcançados, nota-se que os esforços empreendidos pelo governo superaram muito os retornos obtidos - em uma clara assimetria entre custos e benefícios, nos deixando com uma constatação evidente: a ineficácia das políticas industriais estabelecidas durante o período aqui analisado.

Isso posto, faz sentido indagar-se sobre os motivos que desencadearam o fracasso descrito acima - isto é, tentar compreender por que, mesmo lançando mão de um conjunto coerente de ideias e de um complexo arranjo institucional, a política industrial dos governos Lula não conseguiu proporcionar resultados efetivos para o desenvolvimento industrial brasileiro.

\footnotetext{
${ }^{10}$ Das treze entidades instituídas no período: (i) sete destinavam-se à pesquisa e ao desenvolvimento como, por exemplo, a Empresa Brasileira de Hemoderivados e Biotecnologia (Hemobras); (ii) três forneciam crédito ou garantias, como a Agência de Crédito à Exportação do Brasil (EXIM Brasil); (iii) duas objetivavam à promoção de exportações, como Agência de Promoção de Exportações do Brasil (Apex-Brasil); (iv) uma era responsável pela regulação no setor de petróleo, gás natural e biocombustíveis.

${ }^{11}$ Dentre os principais estão a Lei da Inovação, a Lei do Bem e o Estatuto Nacional da Microempresa e Empresa de Pequeno Porte.

${ }^{12}$ No período foram criados e/ou reformados mais de 14 tipos de regimes tributários cujas desonerações somaram mais de $\mathrm{R} \$ 750$ bilhões.

13 Por meio do BNDES houve a criação de mais de 20 linhas de financiamento direcionadas especificamente à indústria, liberando cerca de R\$ 1 trilhão entre 2004 e 2010.

${ }^{14} \mathrm{O}$ governo também ampliou o investimento público em empresas estatais, como a Petrobras e a Eletrobras. Segundo dados do Ministério da Fazenda, esse montante bateu a casa de R $\$ 736$ bilhões no período de 2004 e 2010, confirmando a lógica de intervenção estatal presente no período.

15 Órgão colegiado deliberativo composto por representantes do poder executivo e da sociedade civil designado para propor políticas nacionais e medidas específicas destinadas ao desenvolvimento industrial.
} 


\section{INVIABILIDADE INTELECTUAL, ADMINISTRATIVA E POLÍTICA: EXPLICANDO O FRACASSO}

De acordo com a literatura examinada, parece inegável que os mandatos de Lula foram marcados por uma guinada em relação às políticas industriais, caracterizada por certo ativismo estatal. Nesse sentido, o grande mérito parece ter sido, de fato, a reinserção da indústria na agenda de políticas públicas e o reconhecimento do setor como vetor de desenvolvimento econômico (Suzigan \& Furtado 2006; Almeida 2009; Ferraz 2009; Almeida 2011; Coronel et al. 2014). Essas ações, no entanto, não foram suficientes, como vimos, para que a política industrializante desencadeada durante o período obtivesse êxito.

$\mathrm{O}$ argumento central deste artigo é que isso ocorreu, entre outros fatores, porque as ideias e as medidas formuladas no interior daqueles governos não conseguiram angariar as viabilidades intelectual, administrativa e política, nos termos propostos por Hall (1989). Adicionalmente, defendemos que esse argumento pode ser sustentado pelos achados de parte importante da literatura pertinente. Para demonstrá-lo, selecionamos os trabalhos mais influentes ${ }^{16}$ acerca da política industrializante deste século, sintetizamos seus principais achados e os relacionamos com os três tipos de viabilidades mencionados.

O Quadro 2 reúne o primeiro grupo de argumentos presentes na literatura que nós reunimos e sistematizamos. Como é possível perceber lendo os resumos, embora os autores enfatizem diferentes aspectos do problema, há certa convergência quanto a uma questão geral: a dissonância entre a política desenhada e a política implementada.

\footnotetext{
${ }^{16}$ Foram selecionados artigos no Google Scholar e Scientific Electronic Library Online (SciELO) com os seguintes critérios: (i) termo "política industrial" no título do artigo; (ii) lançado entre 2000 e 2016; (iii) excluindo patentes e citações; (iv) pesquisa somente em páginas em português. Inicialmente, a busca resultou em 309 documentos. Tais ocorrências passaram por alguns critérios de exclusão que procuraram eliminar artigos com: (i) pouca influência (menos de 10 citações); (ii) discussão direcionada somente a alguns setores industriais; (iii) temas periféricos e não estritamente ligados a política industrial; (iv) discussão sobre políticas industriais anteriores a 2003; (v) formatos não acadêmicos como, por exemplo, artigos de jornal. Após a aplicação dos critérios de exclusão, o corpus analítico utilizado reuniu 26 artigos acadêmicos.
} 
Quadro 2: A Inviabilidade Intelectual da Política Industrial Lulista

\begin{tabular}{|c|c|}
\hline Argumento & Descrição \\
\hline $\begin{array}{l}\text { Falta de clareza na } \\
\text { escolha dos setores } \\
\text { priorizados }\end{array}$ & $\begin{array}{l}\text { Além de não evidenciar a metodologia de priorização de setores, a política } \\
\text { industrial lulista utiliza termos vagos ou polissêmicos como setores "voltados } \\
\text { ao fortalecimento da competitividade" ou "relacionados ao fortalecimento } \\
\text { da cadeia produtiva", demonstrando generalidade nos critérios de escolha e } \\
\text { fortalecendo "a suspeita de que tudo é prioritário". }\end{array}$ \\
\hline $\begin{array}{l}\text { Concentração } \\
\text { de esforços } \\
\text { governamentais }\end{array}$ & $\begin{array}{l}\text { O cruzamento entre setores beneficiados pelas políticas e o tipo de instrumen- } \\
\text { to empregado expõe a concentração de reformas horizontais e medidas dire- } \\
\text { cionadas a segmentos mais tradicionais da economia brasileira. Assim, embora } \\
\text { o foco da política seja o incentivo à inovação, a prática revela o direcionamento } \\
\text { de ações a setores competitivos internacionalmente ou a "grandes campeões } \\
\text { nacionais" que teoricamente não necessitariam de benesses governamentais. }\end{array}$ \\
\hline $\begin{array}{l}\text { Ciclos de curto } \\
\text { prazo, coincidentes } \\
\text { com mandatos } \\
\text { eleitorais }\end{array}$ & $\begin{array}{l}\text { As políticas industriais implementadas recentemente coincidiram com os } \\
\text { mandatos de Lula I e II. Tal sincronia confere contradições intrínsecas aos } \\
\text { planos já que as metas foram eleitas para mostrar resultados de curto prazo, e } \\
\text { dentro do ciclo eleitoral, enquanto os efeitos de qualquer política industrial são } \\
\text { naturalmente de longo prazo. }\end{array}$ \\
\hline $\begin{array}{l}\text { Falta de } \\
\text { mecanismos } \\
\text { de avaliação e } \\
\text { contrapartidas }\end{array}$ & $\begin{array}{l}\text { A política industrial do período também não estabeleceu mecanismos formais } \\
\text { de avaliação das empresas incentivadas por meio de renúncias tributárias, } \\
\text { financiamento ou proteção tarifária. Além disso, não foram estabelecidas } \\
\text { medidas de compliance para evitar corrupção e atividades de rent-seeking, } \\
\text { bem como para fomentar contrapartidas (transferência de tecnologia para } \\
\text { firmas locais, transbordamento tecnológico para outros setores, dentre outras). }\end{array}$ \\
\hline $\begin{array}{l}\text { Ausência de } \\
\text { instrumentos } \\
\text { eficazes de } \\
\text { incentivo à } \\
\text { inovação }\end{array}$ & $\begin{array}{l}\text { No conjunto de medidas voltadas à inovação tecnológica não aparecem incen- } \\
\text { tivos ao desenvolvimento de novas tecnologias e adaptadas às necessidades } \\
\text { empresariais. Ao contrário, reduz-se a prática da pesquisa à mera criação de } \\
\text { condições para que empresas absorvam novas tecnologias provocando, no } \\
\text { longo prazo, o abandono da pesquisa fundamental. Além disso, a política } \\
\text { industrial do período não abordou questões sobre patentes, proteção da biodi- } \\
\text { versidade e domínio de empresas estrangeiras. }\end{array}$ \\
\hline $\begin{array}{l}\text { Conflito com a } \\
\text { política econômica }\end{array}$ & $\begin{array}{l}\text { A política macroeconômica utilizou intensivamente dois instrumentos nocivos } \\
\text { ao desenvolvimento industrial. O primeiro se refere à manutenção de } \\
\text { elevadas taxas de juros como principal instrumento de controle da inflação, } \\
\text { encarecendo o financiamento da produção e, sobretudo, desestimulando } \\
\text { investimentos no setor produtivo. O segundo diz respeito à forte volatilidade } \\
\text { cambial, sob o regime de câmbio flutuante, e a sobrevalorização do real que } \\
\text { contrariaram os esforços governamentais na promoção de exportações. }\end{array}$ \\
\hline $\begin{array}{l}\text { Incompatibilidade } \\
\text { com a política } \\
\text { comercial }\end{array}$ & $\begin{array}{l}\text { Embora o país disponha de instrumentos adequados de defesa da } \\
\text { concorrência, o governo brasileiro insistiu em promover políticas que } \\
\text { anulassem a eficácia de tais instrumentos, como a manutenção de proteção } \\
\text { aduaneira, regras de conteúdo local e medidas antidumping. }\end{array}$ \\
\hline $\begin{array}{l}\text { Fraco } \\
\text { reformismo }\end{array}$ & $\begin{array}{l}\text { Embora a política industrial lulista tenha sido concebida sob o viés heterodoxo } \\
\text { de cunho estruturalista-evolucionista (política industrial in books), as medidas } \\
\text { concretas têm se concentrado, prioritariamente, na correção de falhas } \\
\text { sistêmicas e horizontais (política industrial in action). O fraco reformismo } \\
\text { das propostas encontra-se, portanto, na grande distância entre as fases de } \\
\text { concepção, implantação e mensuração dos impactos alcançados. }\end{array}$ \\
\hline
\end{tabular}

Fonte: Elaborado por Stumm (2017) a partir de Almeida (2009), Bresser-Pereira et al. (2016), Canêdo-Pinheiro et. al. (2007), Castilhos (2005), Coronel et al. (2014), Ferraz (2009), Júnior (2015), Schapiro (2015) e Suzigan \& Furtado (2006)

Os argumentos resumidos no Quadro 3, por sua veze, apontam para outra questão geral: a desordem administrativa que caracterizou a estrutura de governança da política industrializante do período em análise. 
Quadro 3: A Inviabilidade Administrativa da Política Industrial Lulista

\begin{tabular}{|c|c|}
\hline Argumento & Descrição \\
\hline $\begin{array}{l}\text { Limitações } \\
\text { da ABDI }\end{array}$ & $\begin{array}{l}\text { A ABDI foi inicialmente idealizada para centralizar e gerenciar as propostas de } \\
\text { política industrial. No entanto, tal órgão foi juridicamente concebido como entidade } \\
\text { de serviço social autônomo, não integrando formalmente a administração pública } \\
\text { direta ou indireta. Nesse sentido, a ABDI enfrenta limites formais e materiais } \\
\text { para coordenar políticas públicas, pois se encontra fora do centro decisório, não } \\
\text { apresentando poder convocatório sobre outras instituições. }\end{array}$ \\
\hline $\begin{array}{l}\text { Carência de } \\
\text { burocracia }\end{array}$ & $\begin{array}{l}\text { Dentro dos órgãos decisórios sobre políticas industriais não há presença de } \\
\text { funcionários públicos altamente qualificados com expertise setorial. O critério da } \\
\text { meritocracia se dá por meio de concursos públicos, com predominância de provas } \\
\text { de conhecimentos gerais, não recrutando especialistas em políticas industriais. }\end{array}$ \\
\hline $\begin{array}{l}\text { Comando } \\
\text { político difuso }\end{array}$ & $\begin{array}{l}\text { Embora o MDIC presida o CNDI, sua liderança política ficou obscurecida no } \\
\text { amplo organograma de instâncias deliberativas superiores ou igualitárias como, } \\
\text { por exemplo, o Conselho de Desenvolvimento Econômico e Social (CNDES), o } \\
\text { Conselho de Governo, Câmara de Política Econômica e a Câmara de Política } \\
\text { de Desenvolvimento Econômico. Seu braço executivo, a ABDI, "nasceu” com } \\
\text { poderes limitados e seu comando também depende de complexa rede de } \\
\text { relações com outros ministérios e instituições mais autônomas, como o BNDES } \\
\text { e a Finep. Além disso, a despeito da existência da ABDI, os formuladores de } \\
\text { política confiaram a coordenação das políticas industriais a estruturas decisórios } \\
\text { paralelas, conformada por secretarias, coordenações, grupos e comitês gestores, } \\
\text { formando uma espécie de hub institucional. Essa superestrutura deliberativa difusa } \\
\text { prejudicou a legitimação da liderança, retardou o processo decisório e dificultou a } \\
\text { articulação de instrumentos e coordenação das ações. }\end{array}$ \\
\hline $\begin{array}{l}\text { Funcionamento } \\
\text { deficiente das } \\
\text { instâncias } \\
\text { deliberativas }\end{array}$ & $\begin{array}{l}\text { O CNDI foi criado com o objetivo de subsidiar a formulação e implementação } \\
\text { de políticas públicas voltadas ao desenvolvimento industrial. Entre } 2005 \text { e } 2007 \\
\text { realizou } 14 \text { reuniões, sendo } 12 \text { ordinárias e } 2 \text { extraordinárias. Após longo período } \\
\text { de inatividade, o CNDI só retorna suas atividades em } 2012 \text { realizando apenas } \\
\text { mais dois encontros, sendo o último registrado em } 2015 \text {. Além do CNDI, outras } \\
\text { instâncias de gerenciamento, como coordenações (sistêmicas e setoriais), } \\
\text { também apresentaram funcionamento irregular prejudicando a legitimidade política } \\
\text { por demonstrar falta de rotina decisória. }\end{array}$ \\
\hline $\begin{array}{l}\text { Cacofonia } \\
\text { decisória }\end{array}$ & $\begin{array}{l}\text { Como o comando político da política industrial lulista foi difuso, sem centralidade } \\
\text { decisória formal e material, o loci institucional se tornou oco e as competências } \\
\text { decisórias foram dispersas em diversos órgãos. Esta conformação dificultou a } \\
\text { coordenação da política e favoreceu certa cacofonia decisória, pois ainda que } \\
\text { fossem promovidos encontros, as medidas de política industrial continuaram } \\
\text { demandando certos processos administrativos e tramitando entre diversas } \\
\text { instâncias formalmente competentes. Nesse sentido, faltou ao arranjo } \\
\text { político-institucional instituído a centralidade decisória e mecanismos de } \\
\text { responsabilização das autoridades envolvidas. }\end{array}$ \\
\hline $\begin{array}{l}\text { Problemas } \\
\text { na prestação } \\
\text { de contas } \\
\text { (accountability) }\end{array}$ & $\begin{array}{l}\text { O arranjo político-institucional também enfrentou problemas na prestação de } \\
\text { contas (accountability), principalmente por três motivos. Primeiro, a seleção do } \\
\text { CNDI não obedece a critérios prévios, públicos e formais. Segundo, o calendário } \\
\text { de reuniões não seguiu rotina pública e o conselho não divulga critérios decisórios } \\
\text { ou revela utilização de ferramentas como a "análise de impacto regulatório", com } \\
\text { métricas de tipo "custo-efetividade". Além disso, o arranjo político-institucional } \\
\text { não conta com procedimento público e satisfatório de prestação de contas, } \\
\text { apresentando medidas adotadas, critérios de escolha e resultados alcançados. }\end{array}$ \\
\hline
\end{tabular}

Fonte: Elaborado por Stumm (2017) a partir de Almeida (2009), Schapiro (2013, 2015) e Suzigan \& Furtado (2006).

Finalmente, embora os argumentos reunidos no Quadro 4 também tenham seus objetos específicos, os mesmos também são atravessados por outra questão de ordem mais geral: a incapacidade dos integrantes do governo em costurar uma 
coalizão com setores estratégicos da burocracia estatal e da sociedade, que pudesse conferir sustentação política ao processo de implementação do projeto industrializante pretendido.

Quadro 4: A Inviabilidade Política da Política Industrial Lulista

\begin{tabular}{|c|c|}
\hline $\begin{array}{l}\text { Baixa } \\
\text { participação das } \\
\text { associações } \\
\text { empresariais }\end{array}$ & $\begin{array}{l}\text { No que se refere à organização dos grupos de interesse, parte da debilidade do } \\
\text { arranjo político-institucional é também tributável ao corporativismo fragmentado, } \\
\text { no qual organizações do sistema corporativo oficial convivem com associações } \\
\text { empresariais formadas espontaneamente. Tal fragmentação continua sendo } \\
\text { "substituída" pelo acesso pessoal que grandes empresários têm junto aos } \\
\text { ministérios, ao BNDES e até mesmo ao Presidente da República, inibindo o } \\
\text { fortalecimento de associações empresariais como instâncias de interlocução entre } \\
\text { governo e setor industrial. }\end{array}$ \\
\hline $\begin{array}{l}\text { Presença de } \\
\text { personalismo } \\
\text { político }\end{array}$ & $\begin{array}{l}\text { Se relação entre Estado e empresariado industrial ocorre por meio de canais diretos } \\
\text { de comunicação com pouca participação das associações, o combustível } \\
\text { dessa forma maleável de representação é a informalidade no qual as relações } \\
\text { público-privadas são estabelecidas a partir de contatos pessoais, extraoficiais, } \\
\text { firmados entre empresas, associações e governo, fortalecendo a tese da ação } \\
\text { política não institucionalizada. Assim, como tais processos carecem de efetividade } \\
\text { institucional, alguns procedimentos decisórios podem ocorrer fora da estrutura } \\
\text { institucional, resultando em decisões ad hoc e na implementação de agendas } \\
\text { pontuais. }\end{array}$ \\
\hline $\begin{array}{l}\text { Baixa } \\
\text { capacidade de } \\
\text { ação política } \\
\text { coordenada }\end{array}$ & $\begin{array}{l}\text { Dada a forma descoordenada e pouco institucionalizada da representação, o } \\
\text { empresariado demonstra problemas de ação coletiva, manifestados pela dificuldade } \\
\text { de aglutinação de interesses nas instâncias deliberativas de política industrial. Em } \\
\text { vez de constituir representação abrangente e institucional, o empresariado industrial } \\
\text { parece voltado para coalizões distributivas, parciais e imediatistas, demonstrando } \\
\text { baixa capacidade para agir de forma coordenada. }\end{array}$ \\
\hline
\end{tabular}

Fonte: Elaborado por Stumm (2017) a partir de Almeida (2009), Schapiro $(2013,2015)$ e Suzigan \& Furtado (2006).

Há, portanto, nos argumentos da literatura pertinente aqui reunidos, três questões gerais que podem ser mobilizadas para explicar por que a política industrial dos governos Lula fracassou: i) dissonância entre teoria e prática, ii) desordem administrativa da estrutura de governança e iii) falta de sustentação política ao projeto pretendido. $\mathrm{O}$ argumento geral desta seção é justamente que cada uma dessas questões corresponde a um dos tipos de viabilidade elaborado por Peter Hall (1989). Senão, vejamos.

A viabilidade intelectual, como já foi dito, depende do reconhecimento de dado conjunto de ideias por uma comunidade epistêmica vinculada aos círculos decisórios pertinentes. Nosso argumento é que, no caso em análise, isso não ocorreu. Esta afirmação, no entanto, não tem a ver com a inexistência de tal comunidade, sabemos que ela existe ${ }^{17}$, mas com a estrutura e o funcionamento dos círculos decisórios - ou, mais especificamente, com a desordem administrativa que, segun-

\footnotetext{
${ }^{17}$ Veja-se, por exemplo, a descrição detalhada sobre o papel do ideário desenvolvimentista no Conselho Nacional de Desenvolvimento Industrial (CNDI) e na Agência Brasileira de Desenvolvimento Industrial
} 
do a literatura, caracterizava sua estrutura de governança. Esse tipo de estrutura decisória, pulverizada e dispersa, proporciona enormes obstáculos à viabilização intelectual de qualquer conjunto de ideias - independentemente de sua orientação teórica.

A mesma dispersão exacerbada de atores, agências e poder decisório também comprometeu o segundo tipo de viabilidade proposto por Hall. Isso porque, segundo esse autor, para adquirir viabilidade administrativa, dado conjunto de ideias precisa contar com o respaldo de agências estatais com poder de agenda e de decisão. Algo bastante improvável quando essas agências, bem como os poderes de agenda e decisão, encontram-se dispersos e/ou sobrepostos - conforme atestado pela literatura que nós reunimos (ver Quadro 3).

Finalmente, a viabilidade política das ideias norteadoras do projeto industrializante dos governos Lula foi obstada pela terceira questão geral elencada acima: a ausência de uma coalizão que pudesse fornecer sustentação política àquelas ideias. Essa sustentação, como vimos, nem precisaria vir de uma convergência ideacional, uma simples convergência de interesses já poderia ser suficiente - desde que se concretizasse em apoio político. Como sabemos, a partir da literatura, isso não ocorreu (ver Quadro 4).

Como base no que foi exposto, é possível defender o seguinte argumento: a política industrial dos governos Lula, embora estivesse ancorada em um conjunto coerente de ideias e tenha mobilizado parte importante da burocracia estatal e da sociedade, não conseguiu angariar viabilidade intelectual, administrativa e política. $\mathrm{O}$ que, seguramente, contribuiu para o seu fracasso.

\section{CONCLUSÃO}

O objetivo deste artigo foi mostrar que ideias importam. Em grande parte, a diferença entre votar em um ou outro partido tem a ver com as ideias que eles defendem nos mais variados campos das políticas públicas. Os governos de Lula foram, no campo da política industrial, orientados por um ideal claramente desenvolvimentista. Pretendia-se levar o capitalismo brasileiro a um novo patamar, por meio de uma política industrial cujo fio condutor era a inovação.

No entanto, como vimos, ideias não se tornam forças sociais a menos que se apropriem de corações e mentes de setores sociais e econômicos estratégicos e se materializem em instituições dotadas de capacidade de coordenação e de poder. A elite estatal que esteve à frente da política industrial dos governos Lula falhou exatamente nesse ponto: em tornar viável o conjunto de ideias que orientou seu projeto industrializante. Nesse sentido, como nós argumentamos, nenhum dos três tipos de viabilidade, nos termos propostos por Peter Hall (1989), foi produzido. 
Em termos mais específicos, a despeito de carregarem atrás de si um corpus ideacional claramente definido, a referida elite falhou em conferir a ele viabilidade intelectual, administrativa e política.

Levar esse argumento em conta, a nosso ver, ajuda a entender por que - a despeito das expectativas geradas e dos recursos (humanos, econômicos, institucionais, etc.) mobilizados - as recentes tentativas de impulsionar o desenvolvimento nacional via industrialização fracassaram. A compreensão mais acurada desse processo importa porque pode evitar erros semelhantes em empreitadas futuras - se e quando as oportunidades aparecerem.

\section{REFERÊNCIAS BIBLIOGRÁFICAS}

Almeida, J.G. de, (2011.) "Alcance e lacunas da nova política industrial”. In Textos para discussão. ${ }^{\circ}$ 196. Campinas: Unicamp.

Almeida, M., (2009). "Desafios da real política industrial brasileira do século XXI". In Texto para discussão. no 1452. Brasília: IPEA.

Amsden, A. H. (2001). The Rise of the Rest: Challenges to the West from Late-Industrializing Economies. New York: Oxford University Press.

Amsden, A. H. (1989). Asia's Next Giant: South Korea and Late Industrialization. New York: Oxford University Press.

Beland, D., (2005). "Ideas and Social Policy: An Institutionalist Perspective". Social Policy and Administration, 39(1), p.1-18. Available at: http://onlinelibrary.wiley.com/ doi/10.1111/j.1467-9515.2005.00421.x/pdf.

Berman, S., (1998). The Social Democratic Moment, London: Harvad University Press.

Bielschowsky, R. (1988). Pensamento Econômico Brasileiro: o ciclo ideológico do desenvolvimentismo. Rio de Janeiro : Ipea/Inpes. Série PNPE, nº19.

Blyth, M., (2003). "Structures do not come with an instruction sheet: interests, ideas, and progress in political science". Perspectives on Politics, 1(04), p.695-706.

Blyth, M., (2001). "The Transformation of the Swedish model. Economic ideas, distributional conflict, and institutional change". World Politics, 54, p.1-26.

Brasil (2003) Ministério do Planejamento, Orçamento e Gestão: Plano Plurianual 2004-2007. PDF.

Brasil (2007). Ministério do Planejamento, Orçamento e Gestão: Plano Plurianual 2008-2011. PDF.

Brasil, (2016a). Plano Brasil Maior.

Brasil, (2016b). Política de Desenvolvimento Produtivo.

Bresser-Pereira, L.C. (2006) “O novo desenvolvimentismo e a ortodoxia convencional”. São Paulo em Perspectiva, v. 20, n. 3, p. 5-24.

Bresser-Pereira, L.C. (2011). "From old to new developmentalism in Latin America”. In: Ocampo, J. A. \& Ros, J (ed.). The Oxford Handbook of Latin American Economics. Oxford: Oxford University Press.

Bresser-Pereira, L.C; Marconi, N. (2008). “Existe doença holandesa no Brasil?” Anais do IV Fórum de Economia de São Paulo, Fundação Getúlio Vargas: São Paulo.

Bresser-Pereira, L.C., Nassif, A. \& Feijó, C.A., (2016). "A reconstrução da indústria brasileira: a conexão entre o regime macroeconômico e a política industrial”. Revista de Economia Política, 36(3), p.493-513.

Campbell, J.L., (1998). "Institutional Analysis and the role of ideas in political economy". Theory and Society, 27(3), p.377-409.

Canêdo-Pinheiro, M. et al., (2007).”Por que o Brasil não precisa de política industrial”. Ensaios Econômicos FGV, (644), p.1-41. 
Castilhos, C.C., (2005). “Contradições e limites da política industrial do Governo Lula”. Indicadores Econômicos FEE, 33(1), p.55-74.

Coronel, D.A., Azevedo, A.F.Z. De \& Campos, A.C., (2014). "Política industrial e desenvolvimento econômico: a reatualização de um debate histórico". Revista de Economia Política, 34(134), p.103-119.

Cox, R.H. e Béland, D., (2013). "Valence, Policy Ideas, and the Rise of Sustainability". Governance: An International Journal of Policy, Administration, and Institutions, 26(2), p.307-328. Available at: http://doi.wiley.com/10.1111/gove.12003.

Curado, M. \& Curado, T., (2016). Uma estimativa dos custos fiscais da política industrial recente (2004 a 2016), Rio de Janeiro. Available at: http://www.ipea.gov.br/portal/index. php?option=com_content $\&$ view $=$ article $\&$ id $=29095 \&$ Itemid $=1 \&$ fbclid $=I w A R 1 I-$ -hFKSWoM0LW21QxELkcnafM3s8xVA3iBGr9qwgonbOui8slCF3SiZUM.

De Toni, J. (2015). “Uma nova governança no padrão de relacionamento público-privado da política industrial brasileira”. Revista de Sociologia e Politica, v. 23, n 55, p. 97-117. DOI 10.1590/1678987315235506.

De Toni, J., (2013). Novos arranjos institucionais na política industrial do governo LULA: a força das novas ideias e dos empreendedores políticos. Tese de Doutorado. Brasília: Universidade de Brasília.

Ferraz, M.B., (2009). "Retomando o debate: a nova política industrial do governo Lula”. Planejamento e Políticas Públicas, 32, p.227-264.

Goldstein, J.,(1993). Ideas, Interests, and American Trade Policy, Ithaca: Cornell University Press.

Goldstein, J. e Keohane, R.O., (1993). “Ideas and Foreign Policy: An Analytical Framework”. In J. Goldstein \& R. O. Keohane, orgs. Ideas and Foreign Policy: Beliefs, Institutions and Political Change. Ithaca: Cornell University Press, p. 3-30.

Gourevitch, P., (1989). “Keynesian Politics: the political sources of economic policy choices”. In P. Hall, org. The Political Power of Economic Ideas. Keynesianism across Nations. Princeton University Press, p. 87-106.

Hall, P., (1986). The Politics of State Intervention in Britain and France, Oxford: Oxford University Press.

Hall, P.A., (1989). The Political Power of Economic Ideias: keynesianism across nations, New Jersey: Cambridge University Press.

Hay, C., (2011). "Ideas and constructions of interests". In D. Béland \& R. H. Cox, orgs. Ideas and Politics in Social Sciences. Oxford: Oxford University Press, p. 65-82.

Heclo, H., org. (1974). Modern Social Politics in Britain and Sweden: from relief to income maintenan$c e$, New Haven and London: Yale University Press.

Hogan, J. e O’Rourke, B., (2014). “The Critical Role of Ideas: a discursive institutionalist approach to understanding change in irishi Industrial policy”. In Midwest Political Science Association Annual Conference. Chicaco. Available at: http://papers.ssrn.com/abstract=2395303.

Júnior, J.T. de A., (2015). "O enigma da política industrial no Brasil”. Revista de Economia Política, 35(3), p.461-474.

Kingdon, J.W., (2014). Agendas, Alternatives, and Public Policies, Essex: Pearson Education Limited.

Morceiro, P. C. (2012). Desindustrialização na economia brasileira no período 2000-2011: abordagens e indicadores. Dessertação de Mestrado. Araraquara: Universidade Estadual Paulista (UNESP).

Naudé, W. (2010) “Industrial Policy: 2010. Old and New Issues”. Working Paper No. 2010/106, United Nations University, World Institute for Development Economics Research.

Nunes, W. (2018). Uma estratégia desenvolvimentosta sem um "Estado Desenvolvimentista”: o caso dos governos Lula. Tese de Doutorado. Curitiba: Universidade Fedral do Paraná.

Oreiro; J. L; Feijó, C. A. (2010). "Desindustrialização: conceituação, causas, efeitos e o caso brasileiro". Revista de Economia Política, v. 30, n. 2. Disponível em: <http://www.scielo.br/scielo. php? script=sci_arttext\&pid=S0101-31572010000200003 >. Acesso em: 16 set. 2013.

Pack, H. e Saggi, K. (2006). "Is there a case for industrial policy? A critical survey”. World Bank Research Observer, vol. 21, issue 2, 267-297. 
Salerno, M.S., (2004). “A política industrial, tecnológica e de comércio exterior do governo federal”. Parcerias Estratégicas, 19, p.13-35.

Salerno, M.S. e Daher, T., (2006). Política Industrial, Tecnológica e de Comércio Exterior do Governo Federal (PITCE): Balanço e Perspectivas, Brasília.

Schapiro, M.G., (2015). "Ativismo estatal e industrialismo defensivo: instrumentos e capacidades na política industrial brasileira". In Textos para discussão. no 1856. Rio de Janeiro: IPEA.

Schapiro, M.G., (2013). "O que a política industrial pode aprender com a política monetária?” Novos Estudos - CEBRAP, (96), p.117-130.

Schmidt, V.A., (2011). "Reconciling ideas and institutions through discursive institutionals". In D. Béland \& R. H. Cox, orgs. Ideas and politics in social science research. New York: Oxford University Press, p. 47-64.

Schmidt, V.A., (2010). "Taking ideas and discourse seriously: explaining change through discursive institutionalism as the fourth 'new institutionalism'”. European Political Science Review, 2(1), p.1-25.

Stumm, M.G., (2017).”O Papel Central das Ideias na Política Industrial Brasileira”. In $9^{\circ}$ Congresso Latinoamericano de Ciência Política. Montevideo: Alacip.

Stumm, M.G., (2016). "Poder Político de Ideias Econômicas: Neodesenvolvimentismo e Política Industrial nos Governos Lula e Dilma". In X Encontro da ABCP. Belo Horizonte.

Suzigan, W. \& Furtado, J., (2006) "Política Industrial e Desenvolvimento". Revista de Economia Politica., 26(102), p.163-185. 